\title{
FITO-HORMÔNIOS NO DESENVOLVIMENTO VEGETATIVO E GERMINAÇÃO DAS SEMENTES DE SORGO SACARINO
}

\author{
ANDRÉ MAY ${ }^{1}$, PAULO CÉSAR MAGALHÃES ${ }^{1}$, MARINA CHAMON ABREU ${ }^{1}$, \\ NÁDIA NARDELY LACERDA DURÃES PARRELLA², MÔNICA MATOSO CAMPANHA ${ }^{1}$, \\ ALEXANDRE FERREIRA DA SILVA ${ }^{1}$, ROBERT EUGENE SCHAFFERT ${ }^{1} \mathrm{e}$ \\ RAFAEL AUGUSTO DA COSTA PARRELLA ${ }^{1}$
}

\begin{abstract}
${ }^{1}$ Embrapa Milho e Sorgo, Sete Lagoas, MG, andre.may@embrapa.br, paulo.magalhaes@embrapa.br, marinachamon@hotmail.com,monica.matoso@embrapa.br, alexandre.ferreira@embrapa.br, robert.schaffert@embrapa.br, rafael.parrella@embrapa.br

${ }^{2}$ Epamig, Prudente de Morais, MG, Brasil, nadia@epamig.br
\end{abstract}

Revista Brasileira de Milho e Sorgo, v.12, n.1, p. 33-43, 2013

\begin{abstract}
RESUMO - Com o objetivo de avaliar o efeito de doses e das épocas de aplicação de diferentes reguladores de crescimento no sorgo sacarino e sua influência sobre o desenvolvimento da planta e a germinação das sementes produzidas, foi instalado em setembro de 2011, em Sete Lagoas, MG, Brasil, na Embrapa Milho e Sorgo, um experimento em casa de vegetação com três ingredientes ativos comerciais (trinexapac-ethyl, paclobutrazol e daminozida), testando-se seis doses para cada produto em duas épocas de aplicação ao longo do ciclo. Observou-se que o ingrediente trinexapac-ethyl foi o mais efetivo na redução do desenvolvimento vegetativo das plantas de sorgo sacarino, quando aplicado duas vezes ao longo do ciclo da cultura, mas com grave prejuízo sobre a qualidade das sementes produzidas.
\end{abstract}

Palavras-chave: Sorghum bicolor; fito-hormônios; acamamento.

\section{PHYTOHORMONES ON VEGETATIVE DEVELOPMENT AND GERMINATION OF SWEET SORGHUM}

\begin{abstract}
Aiming to evaluate the effects of doses and time of application of different growth regulators on sweet sorghum and its influence on plant development and germination of seeds produced, an experiment in a greenhouse was set up in September 2011, in Sete Lagoas, MG, Brazil, at Embrapa Maize and Sorghum, with three commercial active ingredients (trinexapaque-ethyl, paclobutrazol and daminozide), six doses for each product and two application times throughout the cycle. It was observed that the active ingredient Trinexapaque-ethyl was the most effective in reducing the height of sweet sorghum when applied twice during the crop cycle, but it promoted serious damage on seed quality.
\end{abstract}

Key words: Sorghum bicolor; phytohormones; lodging. 
Sorgo sacarino é a denominação dada às plantas da espécie Sorghum bicolor que apresentam elevada produção de massa verde, porte alto e colmos suculentos, com altos teores de açúcares fermentáveis no caldo. Conforme Nan et al. (1994), genótipos de sorgo que apresentam alto teor de umidade no colmo na maturidade e apresentam acima de $8^{\circ}$ Brix no caldo são chamados de sorgo sacarino.

O uso de reguladores de crescimento, aplicados na parte aérea com o objetivo de reduzir o desenvolvimento longitudinal indesejável das plantas, sem ocasionar diminuição na produtividade, pode ser a solução desejada por aqueles envolvidos com o cultivo do sorgo sacarino (Rademacher, 2000). Porém, os efeitos dos reguladores vegetais têm sido inconsistentes: em algumas situações, verifica-se aumento de produtividade, enquanto, em outras, redução dela (Alvarez et al., 2007). A redução no porte das plantas faz com que os metabólicos sejam direcionados para as estruturas reprodutivas (Nóbrega et al., 1999). Os reguladores em plantas cultivadas proporcionam redução da elongação das células do vegetal, além de redução na taxa de divisão celular (Taiz \& Zeiger, 2009).

O trinexapac-ethyl inibe a biossíntese do ácido giberélico, ocasionando redução do crescimento, em razão da menor elongação celular (Lamas, 2001; Fagerness \& Penner, 1998; Amrein et al., 1989). O trinexapac-ethyl atua nas plantas reduzindo a elongação celular no estádio vegetativo, interferindo no final da rota metabólica da biossíntese do ácido giberélico pela inibição da enzima 3-ß-hidroxilase, reduzindo drasticamente o nível do ácido giberélico ativo $\left(\mathrm{GA}_{1}\right)$ e, assim, aumentando acentuadamente seu precursor biossintético imediato $\mathrm{GA}_{20}$. $\mathrm{O}$ efeito e a sua duração são relativos à dose aplicada e ao estádio de aplicação, sendo mais visíveis nos cereais de inverno no estádio de emissão da inflorescência, pela redução dos internódios e do pedúnculo (Heckman et al., 2002).

O daminozide, ácido succínico-2,2-dimetilhidrazida, pertence à classe de compostos que interferem nas últimas etapas da biossíntese das giberelinas por causa das semelhanças estruturais com o ácido 2-oxoglutárico, cossubstrato das enzimas dioxigenases (Rademacher, 2000). De acordo com Dicks \& Charles-Edwards (1973), a concentração inicial de daminozide nas plantas é proporcional à quantidade do regulador aplicada, sendo que a taxa de alongamento das hastes é relacionada à concentração de daminozide nos pontos de crescimento, a qual diminui exponencialmente ao longo do ciclo da cultura. Whypker (1998) sugere a utilização de dosagem entre 4.000 e $8.000 \mathrm{mg} \mathrm{l}^{-1}$ para a inibição de crescimento em girassol envasado.

O paclobutrazol PBZ é um triazol que bloqueia a biossíntese de GA1 (ácido giberélico), diminuindo o desenvolvimento das plantas e sendo capaz de induzir o florescimento sob condições não indutivas. As respostas podem ser muito variáveis, por causa, em parte, dos fatores concernentes à aplicação, à absorção e ao estádio fenológico de aplicação (Santos et al., 2004). De acordo com Silva et al. (2003), o composto ativo alcança os meristemas subapicais da planta, inibindo a oxidação do caureno para ácido caurenoico, o qual é precursor do ácido giberélico. Esse processo resulta em redução dos níveis de todas as formas de GAs (Fletcher et al., 2000), causando reduções na taxa de elongação e divisão celular, sem ocasionar citotoxicidade (Symons, 1989). Os triazóis também podem alterar os níveis de ácido abscísico (ABA), etileno, citocininas (Fletcher et al., 2000) e auxinas (Davis \& Curry, 1991). 
Dessa forma, esse trabalho teve como objetivo avaliar o efeito de doses e épocas de aplicação de diferentes reguladores de crescimento no sorgo sacarino e sua influência sobre o desenvolvimento da planta e a germinação das sementes produzidas.

\section{Material e Métodos}

O experimento foi instalado na Embrapa Milho e Sorgo, localizada em Sete Lagoas, MG, Brasil, situada entre a latitude $19^{\circ} 23^{\prime} \mathrm{S}$ e a longitude $44^{\circ} 10^{\prime} \mathrm{W}$, com altitude média de $726 \mathrm{~m}$. O clima da região é do tipo CWA - Tropical, com chuvas concentradas no verão e um período seco bem definido durante o inverno.

O delineamento experimental utilizado foi em blocos inteiramente casualizados, em esquema fatorial $3 \times 6 \times 2$, com cinco repetições. Os fatores estudados foram: três reguladores de crescimento (trinexapac-ethyl, paclobutrazol e daminozida), com seis doses aplicadas para cada produto $(0 ; 5 ; 15 ; 25$; 35 e $45 \mathrm{ml} \mathrm{l}^{-1}$ de trinexapac-ethyl; $0 ; 10 ; 20 ; 30 ; 40$ e $50 \mathrm{ml} \mathrm{l}^{-1}$ de paclobutrazol; $0 ; 2 ; 3,5 ; 5 ; 6,5$ e $8 \mathrm{~g} \mathrm{l}^{-1}$ de daminozida) e duas épocas de aplicação (uma única aplicação em estágio vegetativo V6 e duas aplicações, sendo uma em V6 e outra em V10), totalizando 36 tratamentos e 180 parcelas. Cada repetição foi composta por duas plantas cultivadas em um vaso com capacidade de 201 . A semeadura foi realizada em 2 de setembro de 2011, utilizando a cultivar de sorgo sacarino BRS 506, da Embrapa.

O experimento foi conduzido em casa de vegetação (tipo estufa) com laterais abertas para permitir a circulação do ar.

Os reguladores de crescimento foram aplicados sobre as plantas com o auxílio de pulverizador costal com $\mathrm{CO}_{2}$ pressurizado e com pressão e vazão constantes. A dose de cada parcela estudada foi aplicada sobre as plantas considerando volume de calda de 1501 ha $^{-1}$, para uma população de plantas considerada de 120.000 plantas ha-1. $^{-1}$

A terra utilizada como substrato foi retirada de barranco composto por solo tipo Latossolo Vermelho Distrófico, textura argilosa. O substrato foi homogeneizado, corrigido com calcário 90 dias antes da implantação do experimento, adubado antes da semeadura com $7 \mathrm{~g}$ vaso $^{-1}$ do formulado 8-28-16 e posteriormente incorporado à profundidade de $5 \mathrm{~cm}$. Foram feitas duas adubações de cobertura utilizado 2,7 g vaso $^{-1}$ do formulado 20-00-20, quando as plantas estavam com 4 e 6 folhas definitivas, respectivamente, para cada adubação de cobertura realizada.

As irrigações foram realizadas diariamente em quantidade equivalente à capacidade de campo da terra utilizada. Realizaram-se também duas pulverizações para o controle de Spodoptera frugiperda (J. E. Smith) (Lepidoptera: Noctuidae) com produtos recomendados para sorgo.

Aos 130 dias após a semeadura, foram avaliadas as características: diâmetro de colmo ( $\mathrm{mm})$, número de folhas, massa seca de colmo (g planta ${ }^{-1}$ ), tamanho do entrenó $(\mathrm{cm})$, massa seca da folha $(\mathrm{g}$ planta $^{-1}$ ), massa seca de panícula (g planta ${ }^{-1}$ ), poder germinativo das sementes logo após a colheita (\%) e plantas acamadas (porcentagem de plantas deitadas). Para a altura da planta, foram realizadas quatro avaliações ao longo do ciclo da cultura aos 42, 67, 89, 132 dias após a semeadura.

Os dados foram submetidos à análise de variância e, em caso de significância, foi feita análise de regressão das médias obtidas. Todas as análises foram realizadas utilizando o programa estatístico Estat, pertencente à Unesp, campus Jaboticabal, SP, Brasil. 


\section{Resultados e Discussão}

Os resultados das análises de variância demonstraram que houve interação tripla altamente significativa para altura da planta $(\mathrm{CV}=8,45 \%)$, massa seca de folhas $(\mathrm{CV}=17,26 \%)$, tamanho médio de entrenó $(\mathrm{CV}=13,94 \%)$ e poder germinativo $(\mathrm{CV}=25,63 \%)$. Houve também interação dupla altamente significativa entre ingrediente ativo e doses para diâmetro de colmo $(\mathrm{CV}=6,45 \%)$, massa seca de panícula $(\mathrm{CV}=25,75 \%)$ e massa seca do colmo $(\mathrm{CV}=26,36 \%)$. Além disso, houve interação dupla altamente significativa entre ingrediente ativo e época de aplicação para as características número de folhas $(\mathrm{CV}=8,48 \%)$ e massa seca da panícula.

Não houve efeito da aplicação dos ingredientes ativos paclobutrazol e daminozida sobre as características estudadas, já que os dois produtos não alteram os valores médios obtidos em relação à testemunha, denotando pouco efeito dos ingredientes sobre o crescimento do sorgo sacarino nas doses estudadas.

A altura das plantas foi reduzida com maiores doses de trinexapac-ethyl, sendo verificada maior redução com duas aplicações dos ingredientes ativos nas plantas de sorgo sacarino, em V6 + V10, conforme se observa na Figura 1. Houve redução de $85 \%$ na altura de plantas com duas aplicações do ingrediente ativo, passando de 2,22 para $0,34 \mathrm{~m}$, respectivamente, entre a dose 0 e $35 \mathrm{ml} \mathrm{l}^{-1}$, no ponto de inflexão da curva.

O comportamento da altura das plantas de sorgo tratadas com trinexapac-ethyl ao longo do ciclo da cultura é apresentado na Figura 2, para a aplicação em V6, e na Figura 3, para a aplicação em V6 + V10, respectivamente. Nas duas épocas de aplicação estudadas (V6 e V6+V10), as doses de 15, 25, 35 e $45 \mathrm{ml}$ foram eficientes para a redução da altura das

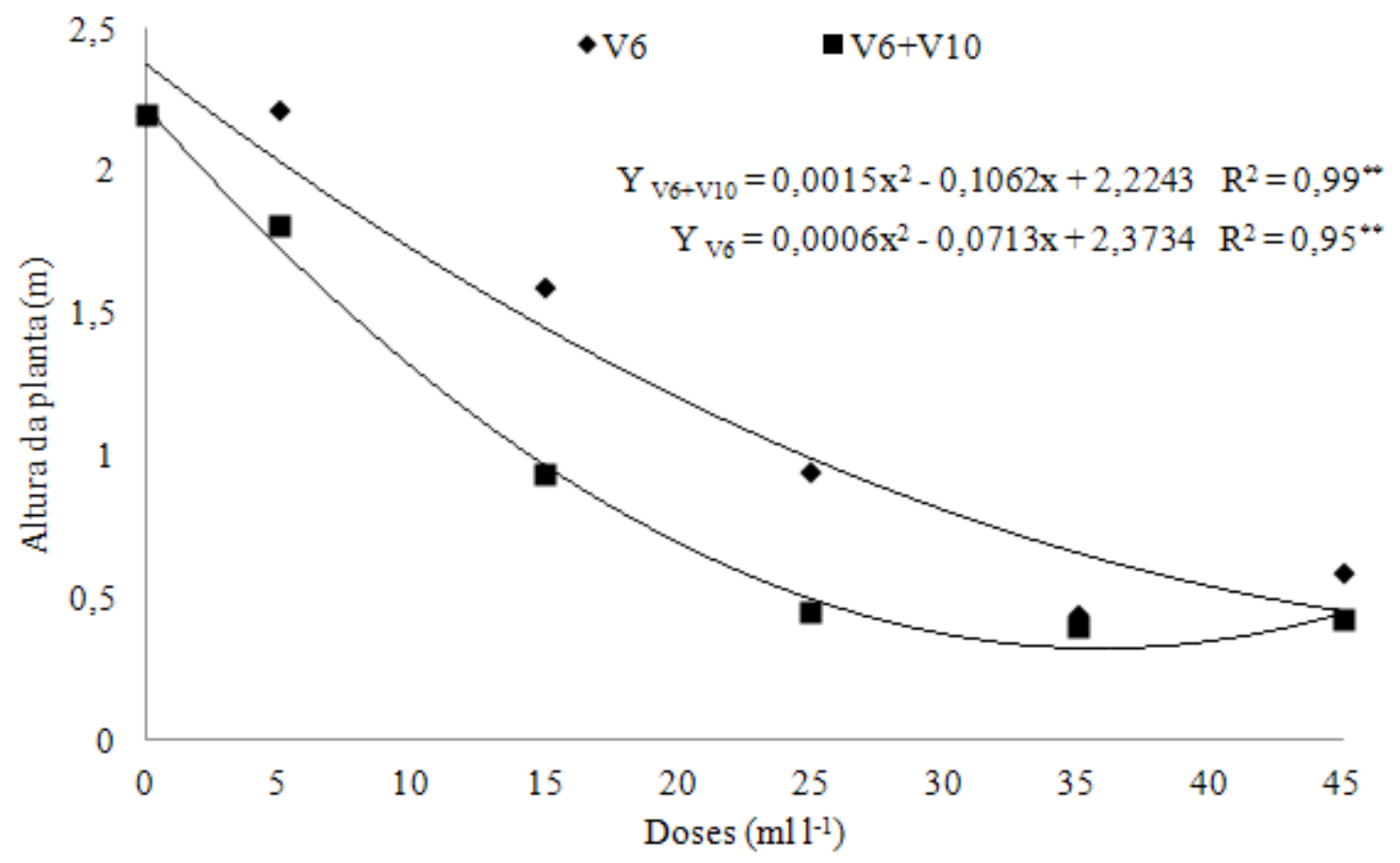

FIGURA 1. Altura da planta de sorgo sacarino em função da aplicação de trinexapac-ethyl em duas épocas de aplicação (V6 e V6 + V10). 


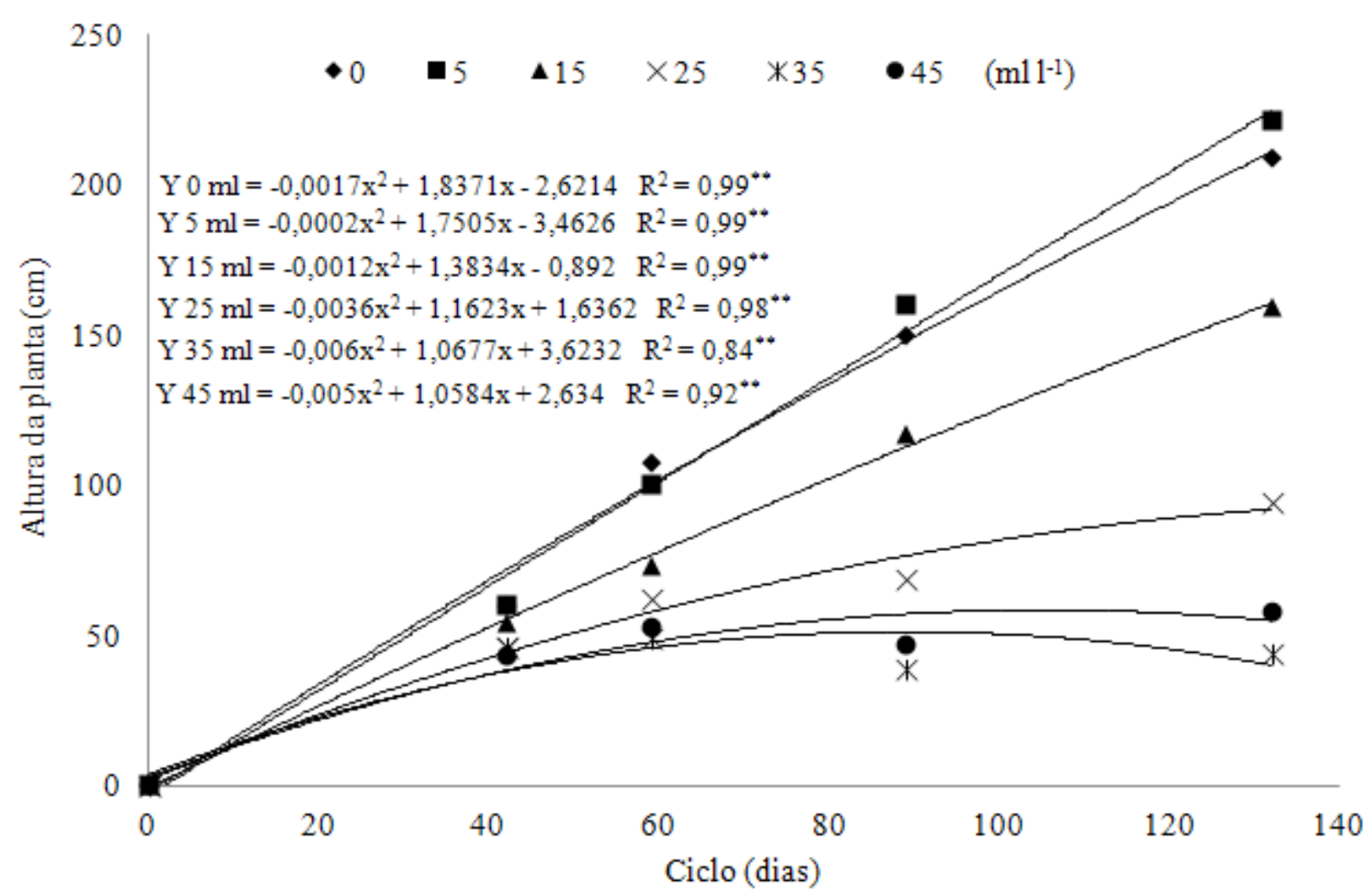

FIGURA 2. Altura da planta de sorgo sacarino ao longo do ciclo em função da aplicação de trinexapac-ethyl em V6.

plantas. Entretanto, quando o ingrediente foi aplicado duas vezes (V6 + V10), a redução foi mais intensa, comparativamente à aplicação somente no estágio V6. As giberelinas formam um grupo de fito-hormônios sintetizados no meio endógeno da planta que estimulam o comprimento do colmo, ressaltando os mecanismos de alongamento celular. De forma geral, inibidores de giberelina têm sido reportados como capazes de ressaltar a atividade metabólica ou a efetividade do ácido abscícico (Korol \& Klein, 2002). Essa redução no nível de ácido giberélico ou na sua sensibilidade, com concomitante redução na altura de planta, é importante para a indução de tolerância a estresses em cereais. O modo de ação do etil-trinexapac inibe parcialmente o transporte de elétrons na mitocôndria, provocando uma redução na respiração celular (Hecjman et al., 2002).

O diâmetro do colmo e o número de folhas por planta somente foram influenciados significativamente com a aplicação de trinexapac-ethyl.

Com o aumento da dose do regulador de crescimento trinexapac-ethyl, houve acréscimo de 1,97 $\mathrm{mm}$ no diâmetro do colmo, passando de $12,65 \mathrm{~mm}$ para 14,61 mm, respectivamente, para as doses $0 \mathrm{e}$ $45 \mathrm{ml} \mathrm{l}^{-1}$, de acordo com a equação $\mathrm{Y}=-0,0009 \mathrm{x}^{2}+$ $0,0842 x+12,649 R^{2}=0,97^{* *}$; e redução de 3,3 folhas nas plantas de sorgo, passando de 11,4 para 8,1 folhas, respectivamente, para as doses 0 e $45 \mathrm{ml} \mathrm{l}^{-1}$, de acordo com a equação $\mathrm{Y}=0,0017 \mathrm{x}^{2}-0,1539 \mathrm{x}+$ $11,39 \mathrm{R}^{2}=0,92^{* *}$. 
Decorrente da redução significativa da altura das plantas com a aplicação de trinexapac-ethyl, houve grande diminuição da massa seca do colmo da planta de sorgo sacarino com o uso do regulador de crescimento, conforme observa-se na Figura 4. A aplicação da maior dose resultou em redução de $87 \%$ na massa de colmo em relação à testemunha. Houve efeito altamente significativo isolado do fator época de aplicação sobre a massa seca de colmos, resultando em redução de $2 \mathrm{~g}_{\text {planta }}{ }^{-1}$ com duas aplicações de trinexapac-ethyl, em relação a apenas uma aplicação do ingrediente por planta, que apresentou média de massa seca de colmo de 22,76 g planta $^{-1}$.

Da mesma forma que para as demais características, o efeito da aplicação dos ingredientes ativos paclobutrazol e daminozida sobre a massa seca do colmo não foi claro, pois as médias obtidas não apresentaram nenhuma tendência que pudesse ser explicada por modelos de regressão polinomial.

A aplicação do ingrediente ativo trinexapac-ethyl teve efeito significativo sobre o tamanho de entrenó em plantas de sorgo sacarino. Com uma aplicação em plantas com 6 folhas, o tamanho de entrenó foi de apenas $0,5 \mathrm{~cm}$ na dose máxima do fito-hormônio, representando uma redução de $97 \%$ em relação à testemunha, como pode ser observado na Figura 5. Por esta razão, a altura das plantas foi extremamente afetada pela aplicação do produto, resultando em grande redução em todas as características vegetativas estudadas. Os ingredientes ativos paclobutrazol e daminozida não apresentaram influência significativa sobre as médias do tamanho do entrenó das plantas tratadas com as diferentes doses dos produtos e épocas de aplicação, mantendo tendência constante entre os tratamentos

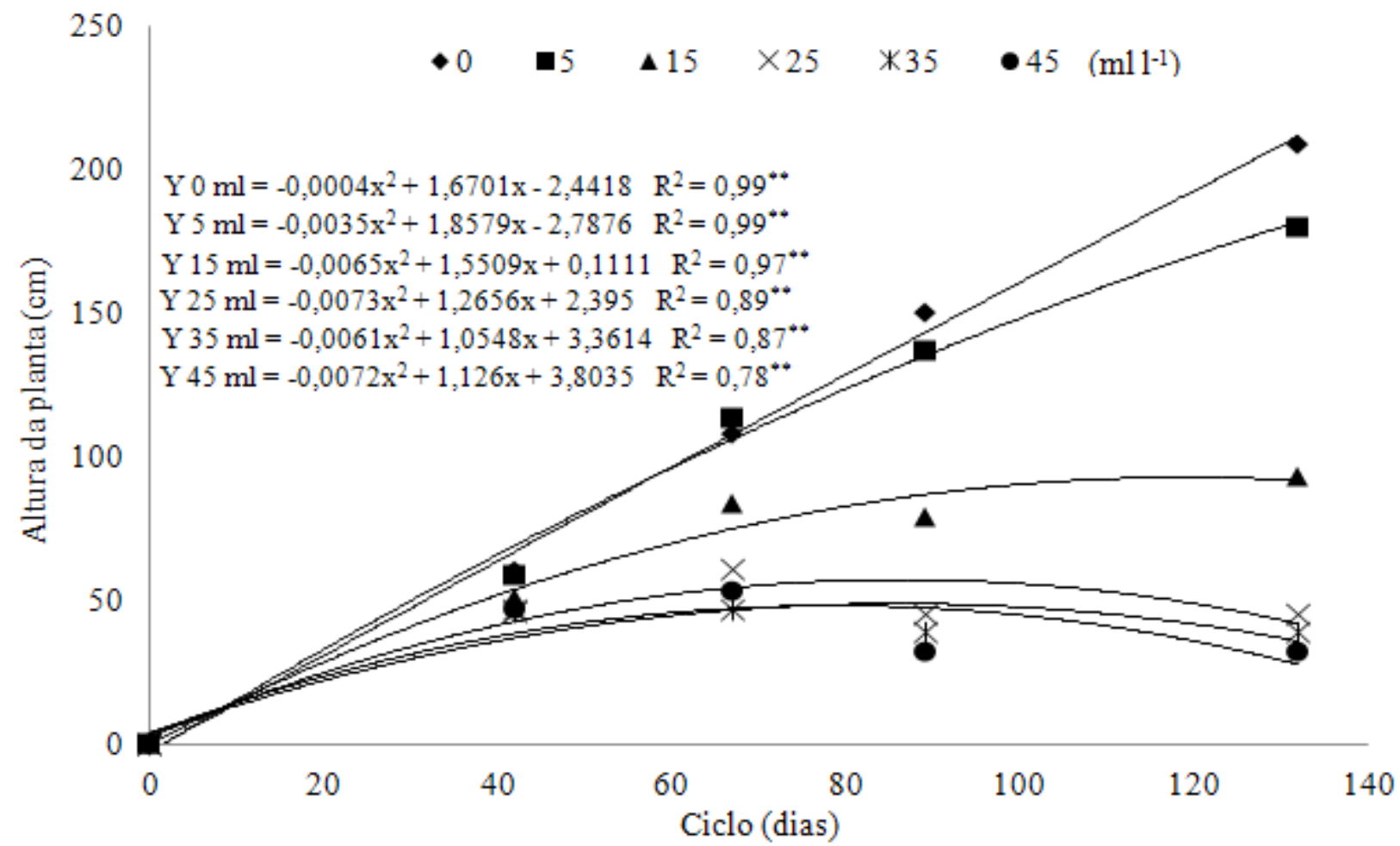

FIGURA 3. Altura da planta de sorgo sacarino ao longo do ciclo em função da aplicação de trinexapac-ethyl em V6 + V10. 


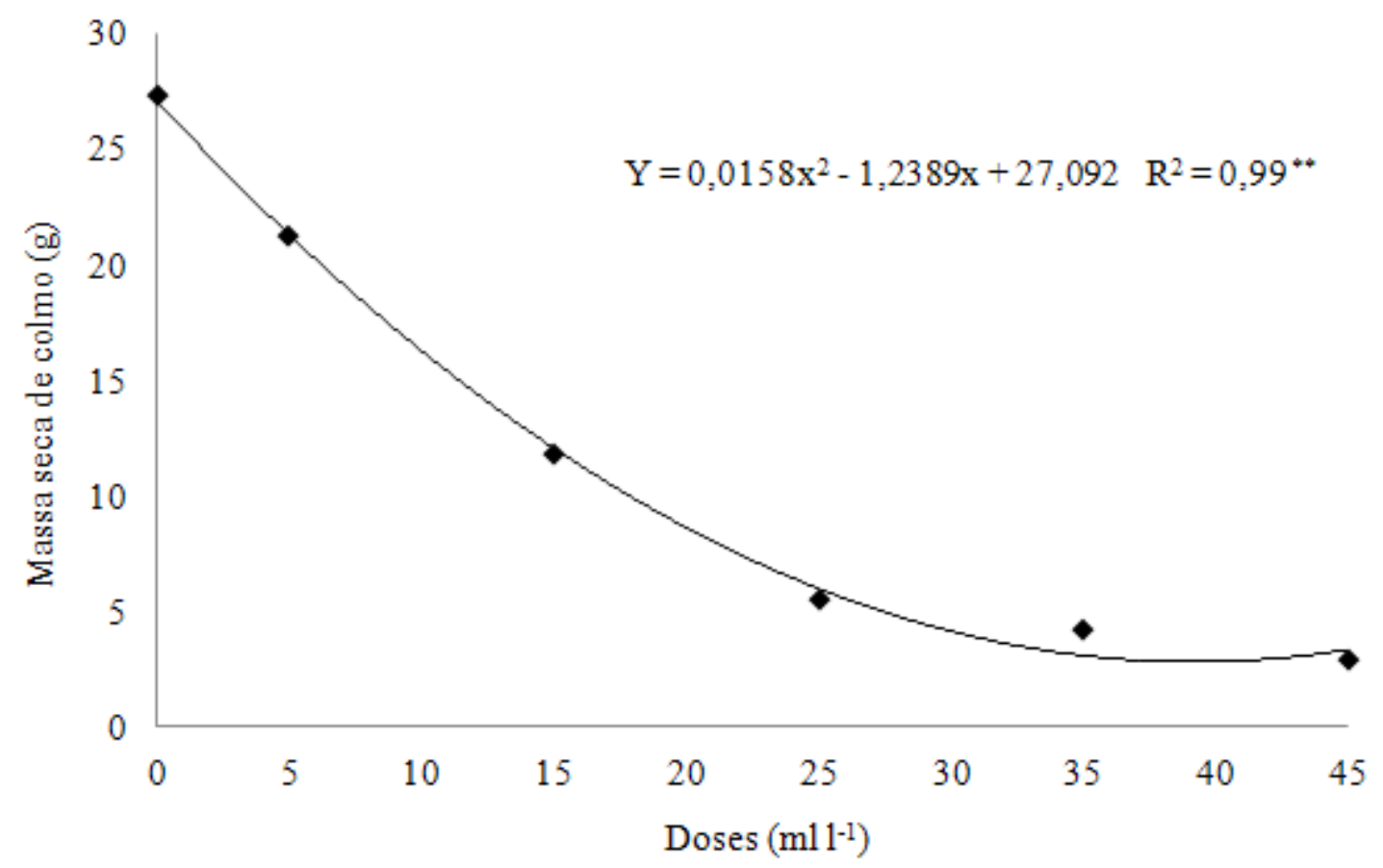

FIGURA 4. Massa seca de colmos de plantas de sorgo sacarino em função da aplicação de trinexapac-ethyl.

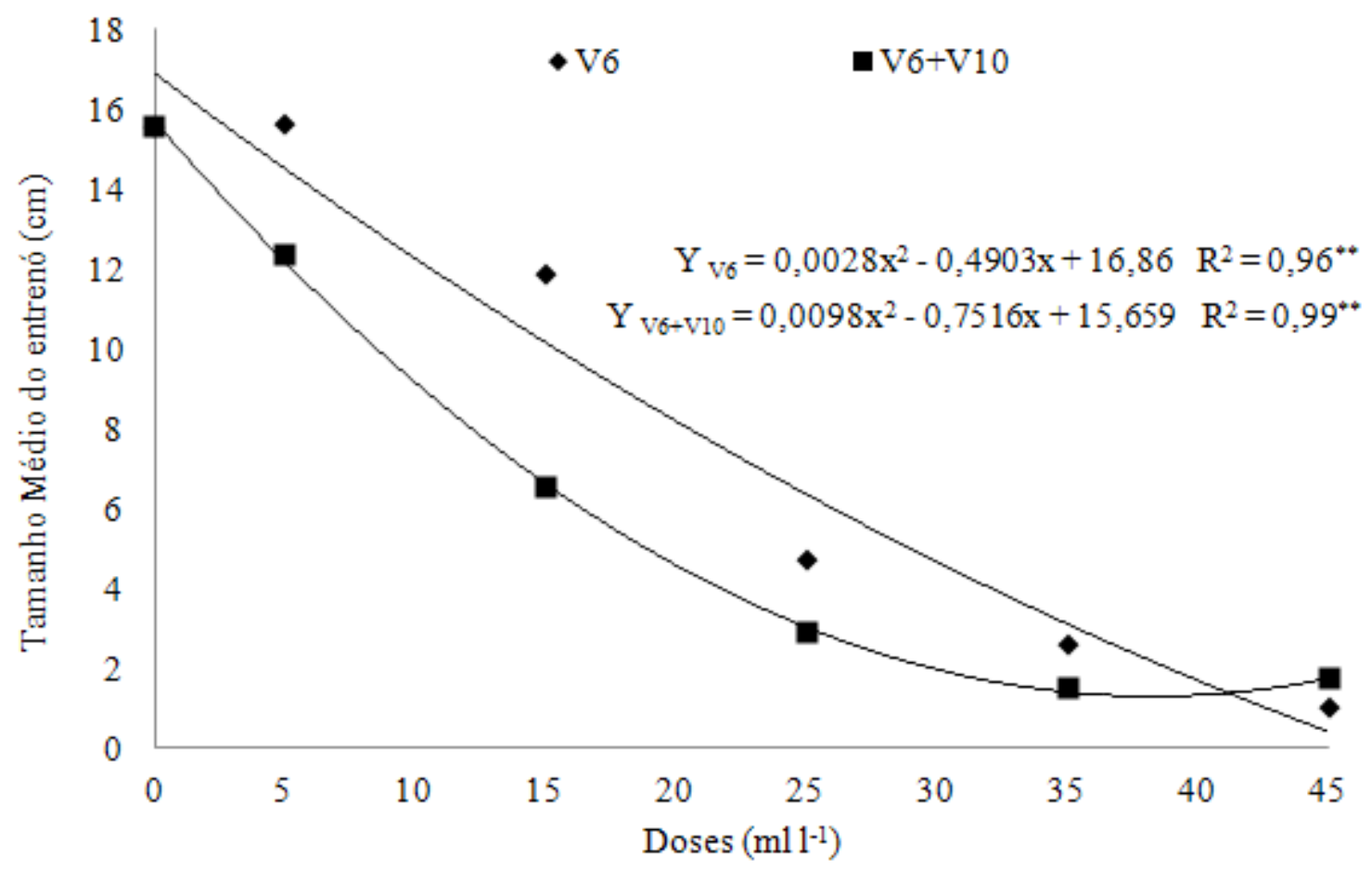

FIGURA 5. Tamanho do entrenó de plantas de sorgo sacarino em função da aplicação de trinexapac-ethyl. 
de 16,6 e $16 \mathrm{~cm}$, respectivamente, para cada produto estudado.

A massa seca de folhas foi reduzida com a aplicação de trinexapac-ethyl, conforme o número de aplicações realizadas. Duas aplicações de ingrediente ativo, realizadas em V6+V10, reduziram em 71,8\% a massa seca de folhas de plantas de sorgo sacarino, sendo que apenas uma aplicação reduziu em 44,6\%, conforme as equações $\mathrm{Y}_{\mathrm{V} 6+\mathrm{V} 10}=0,002 \mathrm{x}^{2}-0,315 \mathrm{x}+$ $14,095 \mathrm{R}^{2}=0,95^{* *}$ e $\mathrm{Y}_{\mathrm{v} 6}=0,0006 \mathrm{x}^{2}-0,1614 \mathrm{x}+13,551$ $\mathrm{R}^{2}=0,72^{* *}$, respectivamente. A redução na altura da planta, atrelada à redução no número de folhas e massa seca de folhas, refletiu diretamente na produtividade de colmos das plantas de sorgo, uma vez que a capacidade fotossintética foi drasticamente afetada, conforme retratado anteriormente. Para paclobutrazol e daminozida, o efeito de redução da massa seca de folhas foi menos pronunciado, com a elevação das doses dos ingredientes ativos, em decorrência da pouca ação dos produtos, nas doses utilizadas, sobre o desenvolvimento das plantas de sorgo sacarino.

A ação do regulador de crescimento trinexapac-ethyl sobre a capacidade fotossintética da planta, por causa da redução da sua área de fotossíntese, afetou o metabolismo da planta, reduzindo inclusive a massa seca da panícula, de acordo com a equação $\mathrm{Y}=$ $0,0116 x^{2}-0,912 x+19,162 R^{2}=0,98^{* *}$, apresentando valores de 19,2 g planta-1, com a aplicação de $0 \mathrm{ml} \mathrm{l}^{-1}$ e 1,61 g planta-1, com $45 \mathrm{ml} \mathrm{l}^{-1}$, resultando em uma redução de 17,5 g planta $^{-1}$ com a aplicação da maior dose do ingrediente ativo, comparativamente à testemunha. O efeito da aplicação dos ingredientes ativos paclobutrazol e daminozida sobre a massa seca da panícula não foi claro, pois as médias obtidas não apresentaram nenhuma tendência que pudesse ser explicada por modelos de regressão polinomial.

A diminuição da massa seca de panícula com a aplicação de reguladores de crescimento é uma

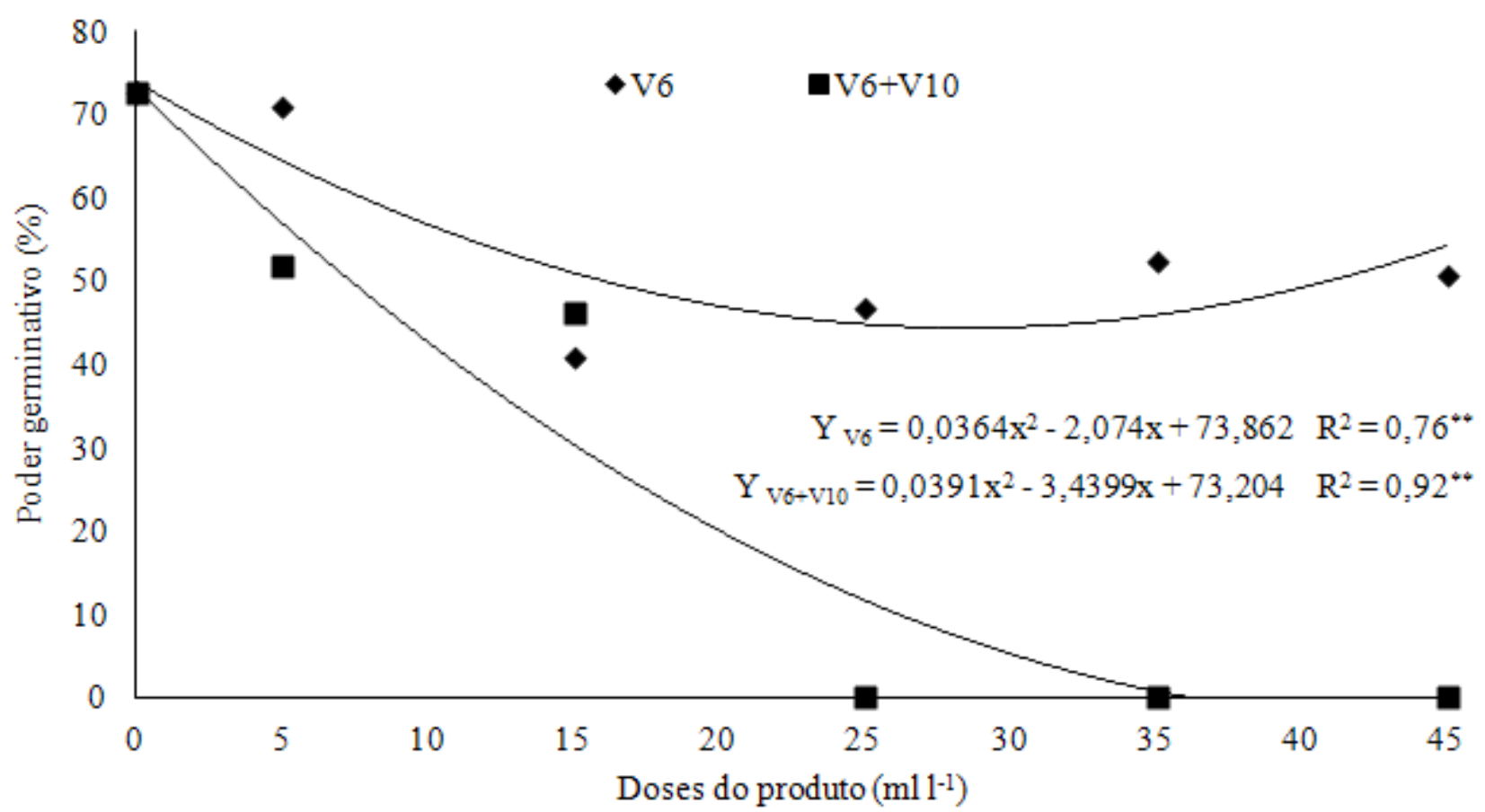

FIGURA 6. Poder germinativo de sementes de sorgo sacarino em função da aplicação de trinexapac-ethyl em V6 e V6 + V10. 
vantagem agronômica para a produção de massa fresca de colmos por causa da redução do risco de acamamento, desde que não haja alta queda na produtividade de colmos por hectare, como ocorreu com a aplicação de doses superiores a $5 \mathrm{ml} \mathrm{l}^{-1}$ de trinexapac-ethyl.

Houve $100 \%$ de plantas acamadas nas testemunhas, sem aplicação de reguladores de crescimento, para todos os ingredientes ativos estudados. Para produção de sementes, a expressiva redução na massa de panículas com maiores doses de trinexapac-ethyl pode ser prejudicial, pois provavelmente haverá uma redução no número de grãos produzidos nessas condições. Por outro lado, ressalta-se que a aplicação de reguladores vegetais pode carrear fotoassimilados para produção de grãos, em detrimento do crescimento vegetativo excessivo.

O poder germinativo das sementes foi influenciado significativamente pela aplicação de trinexapac-ethyl, não sendo significativa para os demais produtos estudados. O uso do ingrediente ativo sobre as plantas de sorgo sacarino resultou em $54 \%$ de germinação das sementes, quando o produto foi aplicado uma única vez em plantas com 6 folhas, na máxima dose estudada (Figura 6), representando uma redução de 26,6\% no poder germinativo das sementes em relação à testemunha. Mas, quando aplicadas duas vezes (V6 + V10) sobre as plantas, o trinexapac-ethyl promoveu perda completa da viabilidade das sementes, principalmente quando as doses utilizadas foram superiores a $25 \mathrm{ml} \mathrm{l}^{-1}$ (Figura 6).

Segundo Heckman et al. (2002), o trinexapac-ethyl atua nas plantas reduzindo a elongação celular no estádio vegetativo, interferindo no final da rota metabólica da biossíntese do ácido giberélico. De acordo com Taiz \& Zeiger (2009), o processo de germinação de sementes de várias espécies exige giberelinas para ativar o crescimento do embrião. E, segundo Swain
\& Singh (2005), a inibição da síntese de giberelinas nas sementes pode afetar negativamente sua germinação, explicando assim a inviabilidade de sementes de sorgo sacarino de plantas que receberam altas doses de trinexapac-ethyl.

Assim, para a produção de sementes através de processos mecanizados de colheita, a busca por plantas mais baixas também é ponto importante, pois, além de reduzir o acamamento, facilita a trilhagem de sementes nas colhedoras por causa da menor massa de colmos e folhas associada a plantas com menor porte, decorrentes da aplicação de reguladores de crescimento.

Contudo, para que a redução no poder germinativo não seja elevada, as doses de trinexapac-ethyl devem ser menores que $5 \mathrm{ml} \mathrm{l}^{-1}$, ou seja, menores que $750 \mathrm{ml} \mathrm{ha} \mathrm{h}^{-1}$ de trinexapac-ethyl, considerando a aplicação de 1501 ha $^{-1}$ de calda, embora ainda representando uma perda significativa do poder germinativo nessa dose estudada (64 e 57\%, respectivamente, para aplicação em V6 e V6 + V10), abaixo do comercialmente aceitável. Assim, sugere-se que a dose adequada do trinexapac-ethyl esteja em níveis menores que 5 $\mathrm{ml} \mathrm{l}^{-1}$, associando a redução do porte das plantas sem queda ao poder germinativo das sementes.

Para a produção de colmos de sorgo sacarino visando a produção de biomassa, seja para fornecimento animal ou para produção de etanol em usinas sucroalcooleiras, a redução do porte da planta está associada à vantagem agronômica de minimização do acamamento em condições de cultivo de campo aberto, mas altas doses do trinexapac-ethyl resultam em reduções elevadas do porte das plantas, diminuindo a produção de massa de colmos por planta. Assim, para o benefício da redução do acamamento, associado à manutenção de altas produções de massa de colmos, as doses de trinexapac-ethyl devem ser menores que $5 \mathrm{ml} \mathrm{l}^{-1}$. 


\section{Conclusões}

$\mathrm{O}$ ingrediente ativo trinexapac-ethyl reduziu o desenvolvimento vegetativo de sorgo sacarino, principalmente quando realizadas duas aplicações do produto ao longo do ciclo, mas altas doses do produto podem reduzir a taxa de germinação das sementes.

\section{Agradecimentos}

Os autores agradecem à Comunidade Econômica Europeia pelos recursos disponibilizados através do Projeto Sweet Fuel da Embrapa Milho e Sorgo, liderado pelo pesquisador Dr. Robert Eugène Schaffert.

\section{Referências}

ALVAREZ, R. C. F.; CRUSCIOL, C. A. C.; TRIVELIN, P. C. O.; RODRIGUES, J. D.; AVAREZ, A. C. C. Influência do etil-trinexapac no acúmulo, na distribuição de nitrogênio $(15 \mathrm{~N})$ e na massa de grãos de arroz de terras altas. Revista Brasileira de Ciência do Solo, Viçosa, MG, v. 31, p. 1487-1496, 2007.

AMREIN, J.; RUFENER, M.; QUADRANTI, M. The uses of CGA 163'935 as a growth regulator in cereals and oilseed rape. In: BRIGHTON CROP PROTECTION CONFERENCE: WEEDS, 1989, Brighton. Proceedings... Surrey: BCPC, 1989. p. 2-12.

CASTRO, P. R. C.; MElOtTO, E. Bioestimulantes e hormônios aplicados via foliar. In: BOARETO, A. E.; ROSOLEM, C. A. Adubação foliar. Campinas: Fundação Cargil, 1989. v. 1, p. 191-235.

DAVIS, T.; CURRY. E. Chemical regulation of vegetative growth. Critical Reviews in Plant Sciences, Boca
Raton, v. 10, p. 151-158, 1991.

DICKS， J. W.; CHARLES-EDWARDS， D. A. A quantitative description of inhibition of stem growth in begetative lateral shoots of Chrysanthemum morifolium by N-dimethylaminasuccinamic acid (Daminozide). Planta, Berlin, v. 112, p. 71-82, 1973.

FAGERNESS, M. J.; PENNER, D. 14 C-Tranexapac- ethyl absortionad translocation in Kentucky bluegrass. Crop Science, Madison, v. 38, p. 1023-1027, 1998. FLETCHER, R. A.; GILLEY, A.; SANKHLA, N.; DAVIS, T. Triazoles as plant growth regulators and stress protectants. Horticultural Reviews, New York, v. 24, p. 55-138, 2000.

GOSS, R. M.; BAIRD, J. H.; KELM, S. L.; CALHOUN, R. N. Trinexapac-ethyl and nitrogen effects on creeping bentgrass grown under reduced light conditions. Crop Science, Madison, v. 42, p. 472479, 2002.

HECKMAN, N. L.; ELTHON, T. E.; HORST, G. L.; GAUSSOIN, R. E. Influence of trinexapac-ethyl on respiration of isolated wheat mitochondria. Crop Science, Madison, v. 42, p. 423-427, 2002.

LAMAS, F. M. Reguladores de crescimento. In: ALGODÃO: tecnologia de produção. Dourados: Embrapa Agropecuária Oeste; Campina Grande: Embrapa Algodão, 2001. p. 238-244.

NAN, L.; BEST, G.; CARVALHO NETO, C. C. Integrated energy systems in China: the cold Northeastern region experience. Rome: FAO, 1994. 475 p.

NÓBREGA, L. B.; VIEIRA, D. J.; BELTRÃO, N. E. M.; AZEVEDO, D. M. P. Hormônios e reguladores do crescimento e do desenvolvimento. In: BELTRÃO, N. E. de M. (Org.). O agronegócio do algodão no Brasil. Brasília, DF: Embrapa Comunicação para a Transferência de Tecnologia; Campina Grande: Embrapa Algodão, 1999. p. 587-602. 
RADEMACHER, W. Growth retardants: effects on gibberellin biosynthesis and other metabolic pathways. Annual Review of Plant Physiology and Plant Molecular Biology, Palo Alto, v. 51, p. 501-531, 2000.

SANTOS, C. H.; KLAR, A. E.; GRASSI FILHO, H.; RODRIGUES, J. D.; PIERRE, F. C. Indução do florescimento e crescimento de tangerineira poncã (Citrus reticulata Blanco) em função da irrigação e da aplicação de paclobutrazol. Revista Brasileira de Fruticultura, Jaboticabal, v. 26, p. 8-12, 2004.

SILVA, C. M. M. S.; FAY, E. F.; JONSSON, C. M. Paclobutrazol: regulador de crescimento vegetal. In: SILVA, C. M. M. S.; FAY, E. F. Impacto ambiental do regulador de crescimento vegetal paclobutrazol. Jaguariúna: Embrapa Meio Ambiente, 2003. p. 11-16. (Embrapa Meio Ambiente. Documentos, 30).

STYER, R. C. Maximizing Chemical Growth retardants.

Greenhouse Product News, Arlington Heights, v.
13, p. 513-529, 2003.

SYMONS, P. R. R. Paclobutrazol: its application and effect on aspects of plant morphology, anatomy, biochemistry and physiology. Pietermaritzburg: University of Natal, 1989. 82 p.

SWAIN, S. M.; SINGH, D. P. Tall tales from sly dwarves: movel functions of gibberellins in plant development. Trend Plants Science, London, v. 10, p. 123-129, 2005.

TAIZ, L.; ZEIGER, E. Fisiologia vegetal. 4. ed. Porto Alegre: Artmed, 2009. 848 p.

ZAGONEL, J.; VENANCIO, W. S.; KUNZ, R. P.; TANAMATI, H. Doses de nitrogênio e densidades de plantas com e sem um regulador de crescimento afetando o trigo, cultivar OR-1. Ciência Rural, Santa Maria, v. 32, p. 25-29, 2002.

WHYPKER, B.; DASOJU, S.; McCALL, I. Guide to successful pot sunflower production. Raleigh: North Carolina State University, 1998. (Horticulture Information Leaflet, 562). 